\title{
Article \\ OKN-007 Alters Protein Expression Profiles in High-Grade Gliomas: Mass Spectral Analysis of Blood Sera
}

\author{
Rheal A. Towner ${ }^{1,2, *}$, James Hocker ${ }^{3, * \mathbb{D}}$, Nataliya Smith ${ }^{1}$, Debra Saunders ${ }^{1}$, James Battiste ${ }^{2}$ and Jay Hanas $^{3} \mathbb{D}$ \\ 1 Advanced Magnetic Resonance Center, Oklahoma Medical Research Foundation, Oklahoma City, OK 73104, USA; \\ Nataliya-Smith@omrf.org (N.S.); Debra-Saunders@omrf.org (D.S.) \\ 2 Department of Neurosurgery, Stephenson Cancer Center, University of Oklahoma Health Sciences Center, \\ Oklahoma City, OK 73104, USA; James-Battiste@ouhsc.edu \\ 3 Department of Biochemistry, University of Oklahoma Health Sciences Center, Oklahoma City, OK 73104, USA; \\ Jay-Hanas@ouhsc.edu \\ * Correspondence: Rheal-Towner@omrf.org (R.A.T.); James-Hocker@ouhsc.edu (J.H.)
}

Citation: Towner, R.A.; Hocker, J.; Smith, N.; Saunders, D.; Battiste, J.; Hanas, J. OKN-007 Alters Protein Expression Profiles in High-Grade Gliomas: Mass Spectral Analysis of Blood Sera. Brain Sci. 2022, 12, 100. https://doi.org/10.3390/ brainsci12010100

Academic Editor: Lucia Lisi

Received: 21 December 2021

Accepted: 10 January 2022

Published: 12 January 2022

Publisher's Note: MDPI stays neutral with regard to jurisdictional claims in published maps and institutional affiliations.

Copyright: (C) 2022 by the authors. Licensee MDPI, Basel, Switzerland. This article is an open access article distributed under the terms and conditions of the Creative Commons Attribution (CC BY) license (https:// creativecommons.org/licenses/by/ $4.0 /)$.

\begin{abstract}
Current therapies for high-grade gliomas, particularly glioblastomas (GBM), do not extend patient survival beyond 16-22 months. OKN-007 (OKlahoma Nitrone 007), which is currently in phase II (multi-institutional) clinical trials for GBM patients, and has demonstrated efficacy in several rodent and human xenograft glioma models, shows some promise as an anti-glioma therapeutic, as it affects most aspects of tumorigenesis (tumor cell proliferation, angiogenesis, migration, and apoptosis). Combined with the chemotherapeutic agent temozolomide (TMZ), OKN-007 is even more effective by affecting chemo-resistant tumor cells. In this study, mass spectrometry (MS) methodology ESI-MS, mass peak analysis (Leave One Out Cross Validation (LOOCV) and tandem MS peptide sequence analyses), and bioinformatics analyses (Ingenuity ${ }^{\circledR}$ Pathway Analysis (IPA $\left.{ }^{\circledR}\right)$ ), were used to identify up- or down-regulated proteins in the blood sera of F98 glioma-bearing rats, that were either untreated or treated with OKN-007. Proteins of interest identified by tandem MS-MS that were decreased in sera from tumor-bearing rats that were either OKN-007-treated or untreated included ABCA2, ATP5B, CNTN2, ITGA3, KMT2D, MYCBP2, NOTCH3, and VCAN. Conversely, proteins of interest in tumor-bearing rats that were elevated following $\mathrm{OKN}-007$ treatment included ABCA6, ADAMTS18, VWA8, MACF1, and LAMA5. These findings, in general, support our previous gene analysis, indicating that $\mathrm{OKN}-007$ may be effective against the ECM. These findings also surmise that $\mathrm{OKN}-007$ may be more effective against oligodendrogliomas, other brain tumors such as medulloblastoma, and possibly other types of cancers.
\end{abstract}

Keywords: OKN-007; high-grade-glioma; rat; blood sera; mass spectrometry (MS); protein profiles; extracellular matrix (ECM)

\section{Introduction}

Gliomas can either be astrocytomas, oligodendrogliomas, ependymomas, or mixed neuronal-glial tumors, with grades varying from I (least malignant) to IV (most malignant) as established by the World Health Organization (WHO) [1]. High-grade gliomas (HGGs) consist of grade III and IV tumors. Unfortunately, patient survival for grade IV gliomas is between 16-22 months with current standard-of-care (SOC) treatments [1], which includes surgical tumor resection, and follow up therapies including radiation, chemotherapy (temozolomide or TMZ (the most commonly used)) and possible treatment with bevacizumab (an antibody therapy targeting the vascular endothelial growth factor or VEGF).

Our group (Towner) has been studying the effect of a small molecular weight (MW), anti-inflammatory molecule, OKN-007 (disodium 4-[(tert-butyl-imino) methyl] benzene1,3-disulfonate $\mathrm{N}$-oxide; or 2,4-disulfophenyl- $\mathrm{N}$-tert-butyl nitrone or, OKlahoma Nitrone 007), for the past decade as a therapeutic agent against HGGs, particularly grade IV glioblastomas (GBM). OKN-007 is currently in phase II multi-institutional clinical trials 
for both recurrent and newly diagnosed GBM patients in combination therapy with TMZ and radiation. In preclinical studies, our group found that $\mathrm{OKN}-007$ was very effective in significantly reducing tumor volumes and elevating animal survival in various high-grade, orthotopic, glioma models, including rat C6 [2], F98 [3,4], mouse GL261 [5], and human adult U87 [3] and G55 [6], as well as pediatric patient-derived GBM [7] and patient-derived diffuse intrinsic pontine glioma (DIPG) [8] xenografts. In addition to effects on animal survival and tumor volumes, OKN-007 was found to significantly reduce necrosis in F98 rat gliomas [9]. In the rat F98 glioma model, we also obtained RT-PCR and microarray data that indicated that $\mathrm{OKN}-007$ acted through the transforming growth factor $\beta$ (TGF- $\beta 1$ ) pathway as a master regulator that down-regulated 57 genes connected with the extracellular matrix (ECM) [6]. In the F98 glioma model, OKN-007 was found to decrease cell proliferation and angiogenesis and increase tumor cell apoptosis [3,9]. OKN-007 was also found to decrease the levels of in vivo free radicals [4]. Additionally, we discovered that OKN-007 is able to augment a decrease in tumor cell growth when co-administered with TMZ in a human G55 xenograft model [6].

The rat F98 high-grade glioma model has various characteristics that are closely associated with human HGGs, including an invasive tumor growth pattern and overexpression of RAS, PDGFB, EGFR, cyclin D1, and D2 [10]. The F98 glioma cell line was initially generated via an intravenous (Iv) injection of ethyl nitrosourea (ENU) transplacentally into pregnant (20 days gestation) Fisher 344 rats, and then developed brain tumors following cloning when intracerebrally injected into syngeneic Fisher 344 rat brains [10].

In this study, blood sera from non-tumor and F98 tumor-bearing rats were subjected to mass spectral (MS) analyses to determine if MS-MS-isolated proteins from these three treatment groups varied and could be used to elucidate distinctive protein profiles of interest that could help establish some further insights, or support our gene data, regarding the mechanism-of-action (MOA) of OKN-007 in high-grade gliomas.

\section{Materials and Methods}

\subsection{F98 Rat Glioma Model}

The study was performed in accordance with the Institutional Animal Care and Use Committee at the Oklahoma Medical Research Foundation. A total of 30 rats (Fisher 344, 4-6 months old, 200-300 g, male) were used (7-8 rats per treatment group; non-tumorbearing rats with or without $\mathrm{OKN}-007$, and tumor-bearing rats with or without $\mathrm{OKN}-007$ ). F98 cells $\left(10^{5}\right.$ in $10-\mu \mathrm{L}$ volume) were implanted intracerebrally using a stereotaxic device ( $2 \mathrm{~mm}$ lateral and $2 \mathrm{~mm}$ anterior to the bregma at a 3-mm depth) in Fischer 344 rats (male 200-250 g) [9].

\subsection{OKN-007 Treatment}

OKN-007 was obtained from Ryss Laboratories (Union City, CA, USA) and was administered to the rats through their drinking water (concentration of $0.018 \% w / v$ ) $[3,9]$. OKN-007 was given continuously, beginning 15 days after F98 glioma cell implantations (tumor volumes were $\sim 30-50 \mathrm{~mm}^{3}$, as determined by morphological magnetic resonance imaging (MRI)), until the end of the study (when tumor volumes reached $\sim 300 \mathrm{~mm}^{3}$, or up to 20 days following treatment) [3,9]. Rats taking normal drinking water were considered as controls. The amount of OKN-007 taken in by either F98 or U87 glioma-bearing rats was established by weighing water bottles each day. Rats were singly housed. Rats were estimated to take in $\sim 10 \mathrm{mg} / \mathrm{kg}$ body weight/day of OKN-007 [3].

\subsection{Blood Collection and Serum Separation from the Whole Blood}

Blood samples $(1 \mathrm{~mL})$ were obtained via tail vein from each rat and left to stand for $1 \mathrm{~h}$ at $37^{\circ} \mathrm{C}$ to allow clotting. Blood samples were then left at $4{ }^{\circ} \mathrm{C}$ overnight to allow contraction of the blood clots. Blood clots were carefully loosened from the sides of the glass tubes using a glass pipet, and the serum was subsequently centrifuged at $4000 \mathrm{rpm}$ 
for $20 \mathrm{~min}$ at $4{ }^{\circ} \mathrm{C}$. Each serum sample was removed from the clot by gently pipetting off into a clean tube using a glass pipet [11]. Samples were stored at $-20{ }^{\circ} \mathrm{C}$.

\subsection{ESI-MS}

Serum ESI-MS and mass peak analysis were performed as described [12-14]. In brief, serum samples were diluted ( $4 \mathrm{uL}$ sera $+1200 \mu \mathrm{L}$ of a mixture of $50 \%$ methanol, $2 \%$ formic acid, and $48 \%$ water) and analyzed by ESI-MS on an ADVANTAGE (Thermo Fisher, Waltham, MA, USA) ion-trap mass spectrometer in positive ion mode. The source consisted of a fused silica tip (Polymicro Technologies: Phoenix, AZ, USA) having a 20 micron inside diameter, 90 micron external diameter, $1.75 \mathrm{Kv}$ source voltage; $0.34 \mu \mathrm{A}$ current, and capillary temp of $195^{\circ} \mathrm{C}$, for each injection. The flow rate was $0.23 \mu \mathrm{L}$ per minute through an Eldex MicroPro HPLC pumping system. Triplicate loop injected MS spectral data were acquired for $15 \mathrm{~min}$ periods. MS signal data were extracted from each file in $1.0 \mathrm{~m} / \mathrm{z}$ units.

\subsection{LOOCV Mass Peak Analysis and Statistics}

As previously described [12-14], post-acquisition MS spectral data processing was performed by locally normalizing each injection data stream set to a total peak intensity value of 100 within a $10 \mathrm{~m} / z$ window along the $150-2000 \mathrm{~m} / z$ observed range. Peaks were identified using standard valley to valley definition and averaged to closest 1 unit $\mathrm{m} / \mathrm{z}$ values. Triplicate data for each sample were also averaged to provide a representative spectral peak pattern for each sample. Leave One Out Cross Validation (LOOCV) analysis format was utilized to assess the similarity and significance of peak patterns between the known (treated tumor, tumor not treated, and no tumor) groups, using t-tests (significance designated at $p<0.05$, one-tailed, unequal variance). LOOCV analysis is used to limit overfitting potential, which is the over-optimistic bias potentially observed when a sample is tested against a set of test variables constructed from a group of samples that also included the sample being tested. The use of the LOOCV procedure helps reduce this bias by serially removing one sample from the dataset and creating a set of test variables from the remaining samples. The variable sample set is then only valid for use against that particular left-out sample. The sample data is then replaced into its proper group, and the next sample is removed, and a new variable set is constructed for it. As graphically presented in Figure 1A, the peak area at each $m / z$ is compared to the remaining samples. If the left-out sample peak is above the PCV, then that peak is scored with the pathology of the group with the higher mean at that peak; otherwise, the peak is scored with the pathology of the group with the lower mean. When all peaks are scored, the percentage of those peaks scored in each group can be reported on the y axis (see Figure 1B-D). Additionally, a database series is created where treatments groups are evenly mixed (referred to as random groups) to assess the potential for identifying random unrelated data patterns using the same methodology and number of significant peaks. Each sera sample is scored against its respective database by performing the above described $\mathrm{LOOCV}$, analyzing each peak between the $400-2000 \mathrm{~m} / \mathrm{z}$ range. 

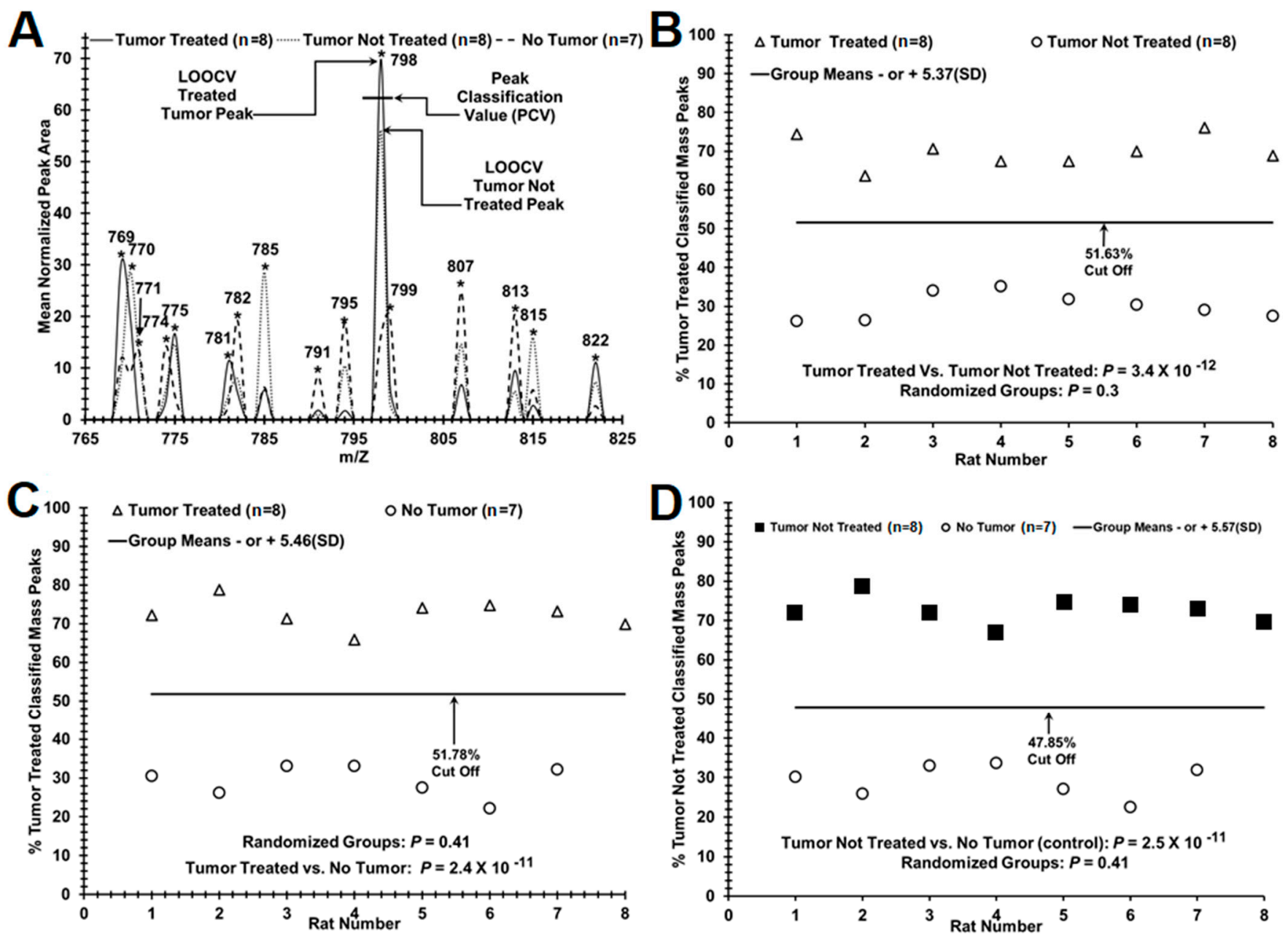

Figure 1. Distinguishing control rodents from treated and untreated brain tumors from each other and from controls using ESI-MS serum mass profiling. ESI-MS (electrospray ionization mass spectrometry) and other procedures were performed as described in the Methods. Panel (A) depicts electrospray MS methodology was used to identify, quantify, and classify significant sera $m / z$ peaks signal into tumor treated (solid line) or tumor not treated (dotted line) peak area descriptors determined by mass peak areas are averages from 8 individual serum samples per category. No tumor controls (dashed line). Panel (B) shows a difference in distribution between sera from tumor treated rodents $(\Delta$, open triangles) versus sera of untreated rodents $(\bigcirc$, open circles) based on significant "\% of tumor treated classified mass peaks", using the mass peak analyses described in the Materials and in panel A. Panel (C), mass peak distribution difference between sera from tumor treated animals $(\Delta$, triangles) and controls. Panel (D), mass peak distribution difference between sera from tumor non-treated animals $(\boldsymbol{\square}$, closed squares), and no tumor controls $(\bigcirc$, open circles). $p$-values for each group separation are provided. "Cut-offs" are greater than five standard deviations (S.D.) below \% mass peaks mean and are used for test metric analysis. * indicates the $\mathrm{m} / \mathrm{Z}$ molecular mass peak for each major peak identified.

\subsection{Tandem MS/MS and Bioinformatic Analysis}

For tandem MS peptide sequence analysis [14], samples from sera were randomly selected and re-analyzed in the MS ion-trap instrument via selected reaction monitoring (SRM) MS/MS without chromatographic separation of sera. Mass peaks, determined in the ESI-MS positive mode and found to be significant from the LOOCV analysis $(p<0.05)$, were chosen for MS/MS isolation and fragmentation. The significant peaks were between a $500-1100 \mathrm{~m} / \mathrm{z}$ range and are a subset of the peaks represented in Figure 1B. Identification of peak proteins was established using SEQUEST Proteome Discoverer 1.0 (Thermo 
Fisher) employing the "no cleavage" setting on a rat database created through the Discoverer software from an NCBI non-redundant database downloaded on 6 October 2015. Peptides/proteins MS/MS identification from samples involved a cross-correlation value (Xcorr) of 1.8 or better [15]. For Ingenuity ${ }^{\circledR}$ Pathway Analysis (IPA ${ }^{\circledR}$, QIAGEN Germantown, MD, USA www.qiagen.com/ingenuity; accessed on 1 January 2022), associated gene names and the number of identified MS/MS sequences were each imported as base-2 log ratios of untreated tumor sequence "hits" divided by treated tumor "hits". Detected pathways were manually inspected and verified using Medline/PubMed.

\subsection{Test Metrics}

A test/procedure diagnostic value is defined by sensitivity, specificity, predictive value, and efficiency $[16,17]$. The sensitivity of the test was determined from $\mathrm{TP} /(\mathrm{TP}+\mathrm{FN})$, where TP was the number of true positives for disease presence, and FN was the number of false negatives for disease presence. Specificity was calculated from TN/(TN+FP), where $\mathrm{TN}$ is the number of true negatives and FP is the number of false positives. Rat brain tumor treated, untreated, and control TP, FP, TN, and FN values were defined using cutoffs of two standard deviations below the mean "\% of classified mass peaks patient serum peaks (Figure 1B-D).

\section{Results}

From previous studies, we were able to show that F98 glioma-bearing rats treated with OKN-007 were able to extend animal survival by 9 days (162 equivalent human days; one 6-month-old rat day is an estimated 18 days of human life [18-20] following treatment, and significantly decrease tumor volumes $\sim 3$-fold [3]. We also previously established that the TGF- $\beta 1$ pathway was the master regulator that down-regulated 57 genes associated with the ECM [6]. In this study, MS was used to determine the differentiation of protein expressions when comparing non-tumor-bearing and tumor-bearing rats' blood sera from those treated with OKN-007 (both tumor- and non-tumor-bearing).

Figure 1A illustrate the mean areas of a small number of the significant ESI- MS mass peaks (in $m / z$ units, mass divided by charge) able to discriminate sera from rodents with drug-treated brain tumors (solid lines), rodents with untreated tumors (dotted lines), and control rodents (dash lines). Major serum mass peak mean areas (higher value) from rodents with treated brain tumors include $m / z 769,775,781$, and 798, for untreated tumors peaks $770,785,815$, and peaks 782,795 , and 807 from control animals. This $m / z$ region is only one of many analyzed (total range $400-2000 \mathrm{~m} / z$ ), and a large number of significant peak changes likely is contributing to the brain tumor discrimination ability of this technology. Peak 798 exhibits a Peak Classification Value (PCV) metric area midpoint by which all peaks in the "left in" LOOCV database possess and are similarly assigned and used to classify the group designations (tumor treated, untreated, or control) of the mass peaks found in individual "left out" serum samples. A "left out" peak above this midpoint is allocated to the higher value classifier (tumor treated for this peak), and a "left out" peak below this midpoint is assigned to the lower value classifier (tumor not treated for this peak). In this way, an individual "left out" serum sample is assigned a "\% of tumor treated classified mass peaks" or a "\% of tumor not treated classified mass peaks", and that \% value is plotted on the $y$-axis for that patient number in Figure 1B-D. Figure 1B illustrates the application of this LOOCV process using mass peak PCVs for distinguishing serum from rodents with brain tumors treated with a drug from brain tumor untreated animals. When this "\% tumor treated classified mass peaks" is plotted versus animal number, a distribution plot is obtained (in which a clear demarcation is observed between tumor treated (triangles) versus tumor untreated (circles). The $p$-value for this distribution difference is very low (10-12 range), and that value becomes non-significant (0.3) when these two sample groups (tumor treated and untreated) are mixed together in a random fashion followed by the same LOOCV mass peak analysis. 
The randomized LOOCV database is composed with the randomization of group membership, consisting of the same number of peaks as the original database, and is an attempt to remove the effects of the known pathology, as well as observe the potential separation effects occurring by random, undefined, or unexpected influences. The increase in $p$-value upon randomization is consistent with minimal/reduced over-fitting of the original data set and with the presence of a physiological basis for the group discriminations.

Table 1 provide the LOOCV standard deviations and other metrics of rat brain tumor ESI-MS peak distribution data presented in Figure 1, using the nomenclature from predictive value theory $[16,17]$. The pathological groups tested in binary fashion are catalogued in the far-left column. The means and their standard deviations (SD) are from the y-axis (\% classified peaks) of panels B-D in Figure 1 and are all still well separated and have narrow SD boundaries for each of the groups tested. The $p$-values from the true binary group distribution differences and the mixed randomized binary group distribution differences are indicated. Physiological values in the original distribution differences are shown by the very substantial increases in $p$-values when the groups are randomized. At this stage in the studies with these $n$ values, the true positive (test specificity), true negative (test sensitivity), false positive, and false-negative rates are all unit values.

Table 2 exhibit the peptides identified by tandem MS/MS (listed using protein abbreviations) of different protein sequences identified from discriminating sera sample $m / z$ mass utilized in Figure 1B. MS/MS analysis was performed in sera from all rats in both the untreated tumor $(n=8)$ and the treated tumor $(n=8)$ groups. A subset of mass peaks determined to be significant from the LOOCV analysis distinguishing untreated brain tumor animals from treated brain tumor animals was chosen for MS/MS isolation and fragmentation. In all, 36 significant discriminatory mass peaks at unit Dalton resolution were obtained between a 500-1100 $\mathrm{m} / \mathrm{z}$ range and are a subset of the peaks represented in Figure 1, panel B of the separation figure. The top 75 proteins are presented in Table 2. Proteins were considered more likely to occur in serum if they were observed more frequently (minimum two or more unique peptides found in two or more serum samples per group at a cross-correlation $(X$ cor) value of 2.0 or greater. This Table represents a phenotypic "snapshot" of the brain tumor condition in this rat model related to treatment effects and the systemic changes seen in the blood serum. Supplementary Table S1 outlines the ratios of observations used in IPA for the peptides in Table 2 when comparing untreated to OKN-007-treated serum samples.

Figure 2 exhibit IPA analysis using the MS/MS results in Table 2 as well as other identified peptides in the "untreated" vs. "treated" peptide analysis from this study. In total, $60 \%$ of the proteins indicated in these Figure 2 pathways are included in the "top 75" unique peptide/protein "hits" in Table 2. The remaining 40\% are found in the MS/MS results in this study but at lower "number of unique peptides" and "number of MS/MS hits" values. It is noted that zero values suggest a protein that was observed but did not change due to the treatment. Although other pathways could also be identified from these peptides/proteins, the three presented pathways here [tumorigenesis of malignant tumor; abnormal morphology of the nervous system; and tumor in nervous system] represent the simplest representation after duplicating smaller pathways containing the same proteins and similar description/function pathways, were removed. Figure 2 possibly represent a "snapshot" with systemic implications of what could be considered physiological changes related to the treatment of the tumor. 
Table 1. LOOCV Statistics and test metrics for rodent brain tumor and control ESI-MS serum mass profiling.

\begin{tabular}{|c|c|c|c|c|c|c|c|}
\hline $\begin{array}{l}\text { Test Metrics (Group } 1 \text { vs. Group 2, } \\
n \text { Values) }\end{array}$ & Mean (SD) & Mean (SD) & $\begin{array}{c}\text { True } \\
\text { Positive Group } 1\end{array}$ & $\begin{array}{l}\text { False Positive } \\
\text { Group } 1\end{array}$ & $\begin{array}{l}\text { True Negative } \\
\text { Group } 2\end{array}$ & $\begin{array}{l}\text { False Negative } \\
\quad \text { Group } 2\end{array}$ & $\begin{array}{c}p \text {-Value } \\
\text { True Pathology } \\
\text { [Random Groups] }\end{array}$ \\
\hline $\begin{array}{l}\text { Tumor Treated (8) vs. Tumor Not } \\
\text { Treated (8) [ROC area = 1] }\end{array}$ & $\begin{array}{c}0.70 \\
(0.03)\end{array}$ & $\begin{array}{c}0.30 \\
(0.03)\end{array}$ & $\begin{array}{c}8 / 8 \\
(100 \%)\end{array}$ & $\begin{array}{l}0 / 0 \\
(0 \%)\end{array}$ & $\begin{array}{c}8 / 8 \\
(100 \%)\end{array}$ & $\begin{array}{l}0 / 0 \\
(0 \%)\end{array}$ & $\begin{array}{l}3.4 \times 10^{-12} \\
{[0.3]}\end{array}$ \\
\hline $\begin{array}{l}\text { Tumor Treated }(n=8) \text { vs. No Tumor } \\
\text { (control: } n=7) \text { [ROC area }=1]\end{array}$ & $\begin{array}{c}0.73 \\
(0.03)\end{array}$ & $\begin{array}{c}0.29 \\
(0.04)\end{array}$ & $\begin{array}{c}8 / 8 \\
(100 \%)\end{array}$ & $\begin{array}{l}0 / 0 \\
(0 \%)\end{array}$ & $\begin{array}{c}7 / 7 \\
(100 \%)\end{array}$ & $\begin{array}{l}0 / 0 \\
(0 \%)\end{array}$ & $\begin{array}{c}2.4 \times 10^{-11} \\
{[0.41]}\end{array}$ \\
\hline $\begin{array}{l}\text { Tumor Not Treated (8) vs. No Tumor } \\
\text { (control: } n=7 \text { ) [ROC area }=1]\end{array}$ & $\begin{array}{c}0.73 \\
(0.03)\end{array}$ & $\begin{array}{c}0.29 \\
(0.04)\end{array}$ & $\begin{array}{c}8 / 8 \\
(100 \%)\end{array}$ & $\begin{array}{l}0 / 0 \\
(0 \%)\end{array}$ & $\begin{array}{c}7 / 7 \\
(100 \%)\end{array}$ & $\begin{array}{l}0 / 0 \\
(0 \%)\end{array}$ & $\begin{array}{l}2.5 \times 10^{-11} \\
{[0.41]}\end{array}$ \\
\hline
\end{tabular}

LOOCV (leave one out cross-validation); SD (standard deviation); ROC (receiver operator characteristic) curve; $p$-value from Student's $t$-test.

Table 2. Peptides/proteins identified by tandem MS/MS to be elevated or decreased in sera from rat brain tumor drug-treated or untreated animals.

Decreased in Serum from Treated Brain Tumor Animals Relative to Non-Treated Animals

\begin{tabular}{|c|c|c|c|c|c|}
\hline Protein & Pathway (IPA) & Protein & Pathway (IPA) & Protein & Pathway (IPA) \\
\hline ABCA2 & $\mathrm{B}, \mathrm{C}, \mathrm{CN}, \mathrm{G}, \mathrm{MM}, \mathrm{MN}, \mathrm{T}$ & DDX1 & MM & NAT6 & \\
\hline $\mathrm{ACO} 2$ & $\mathrm{C}, \mathrm{N}$ & DHTKD1 & $\mathrm{B}, \mathrm{C}, \mathrm{CN}, \mathrm{G}$ & NOTCH3 & $\mathrm{B}, \mathrm{C}, \mathrm{CM}, \mathrm{CN}, \mathrm{G}, \mathrm{N}$ \\
\hline ADGRE1 & & DPYSL3 & $\mathrm{C}, \mathrm{MN}, \mathrm{N}$ & NSUN6 & \\
\hline AHR & $\mathrm{CM}, \mathrm{MM}, \mathrm{N}$ & $\mathrm{FH}$ & $\mathrm{CM}, \mathrm{MM}, \mathrm{N}, \mathrm{T}$ & PDE11A & $\mathrm{C}$, \\
\hline ATP5B & $\mathrm{B}, \mathrm{CN}, \mathrm{G}, \mathrm{T}$ & INTS12 & & PIGS & \\
\hline CACHD1 & & IPO9 & $\mathrm{T}$ & SMG5 & $\mathrm{T}$ \\
\hline CES2 & & ITGA3 & $\mathrm{C}, \mathrm{MM}, \mathrm{MN}, \mathrm{N}, \mathrm{T}$ & TMEM132D & C, \\
\hline CFTR & $\mathrm{C}, \mathrm{CN}, \mathrm{G}, \mathrm{MM}, \mathrm{T}$ & KMT2D & $\mathrm{C}, \mathrm{CM}, \mathrm{CN}, \mathrm{G}$ & TTBK2 & $\mathrm{N}$ \\
\hline CRB1 & $\mathrm{MN}$ & LOC690425 & & VCAN & C, CM, MM, MN, N \\
\hline CSF1R & $\mathrm{C}, \mathrm{CM}, \mathrm{CN}, \mathrm{G}, \mathrm{MM}, \mathrm{N}$ & MYCBP2 & $\mathrm{C}, \mathrm{CN}, \mathrm{G}, \mathrm{MM}, \mathrm{MN}$ & XRCC5 & $\mathrm{C}, \mathrm{CN}, \mathrm{MM}, \mathrm{N}$ \\
\hline CUBN & $\mathrm{C}, \mathrm{T}$ & MYH3 & & ZBTB37 & \\
\hline
\end{tabular}


Table 2. Cont.

\begin{tabular}{|c|c|c|c|c|c|}
\hline \multicolumn{6}{|c|}{ Increased in Serum from Treated Brain Tumor Animals Relative to Non-Treated Animals } \\
\hline Protein & Pathway (IPA) & Protein & Pathway (IPA) & Protein & Pathway (IPA) \\
\hline ABCA6 & & GRID2 & $\mathrm{MM}, \mathrm{MN}, \mathrm{N}, \mathrm{T}$ & MUC16 & \\
\hline $\mathrm{ABCC} 8$ & $\mathrm{CN}, \mathrm{MM}, \mathrm{N}, \mathrm{T}$ & HADHA & $\mathrm{MM}, \mathrm{N}$ & MUC19 & \\
\hline ACO1 & $\mathrm{C}, \mathrm{T}$ & LAMA5 & $\mathrm{C}, \mathrm{CM}, \mathrm{N}$ & MUSK & $\mathrm{B}, \mathrm{CN}, \mathrm{G}, \mathrm{MM}, \mathrm{MN}, \mathrm{N}$ \\
\hline ACOX1 & $\mathrm{C}$ & LOC102554371 & & PAFAH2 & $\mathrm{N}$ \\
\hline ADAMTS18 & $\mathrm{C}$, & LOC103691264 & & PCDHA4 & $\mathrm{B}, \mathrm{C}, \mathrm{CN}, \mathrm{G}$ \\
\hline ADGRF5 & $\mathrm{C}, \mathrm{CM}, \mathrm{MM}$ & LOC685544 & & PCYT1A & MM, T \\
\hline AMACR & $\mathrm{MM}, \mathrm{N}$ & LOR & C, & PLCE1 & $\mathrm{C}, \mathrm{N}$ \\
\hline CACNA1D & $\mathrm{C}, \mathrm{CM}, \mathrm{CN}, \mathrm{MN}, \mathrm{T}$ & MACF1 & MM & PTPN22 & $\mathrm{N}$ \\
\hline CRYBG3 & & MCM3AP & MM, T & REV3L & $\mathrm{MM}, \mathrm{N}$ \\
\hline DHRSX & $C$, & MFSD12 & & TBC1D23 & \\
\hline DSCAM & $\mathrm{C}, \mathrm{MM}, \mathrm{MN}$ & MICAL2 & C, & TENM2 & $\mathrm{C}, \mathrm{MN}$ \\
\hline EEF1AKMT1 & & MRVI1 & MM & TUBA4A & \\
\hline EXNEF & $\mathrm{C}$ & MTTP & & VWA8 & \\
\hline
\end{tabular}

Pathways were identified by Ingenuity Pathway Analysis (IPA) software; abbreviations: B (brain astrocytoma); C (cancer of cells); CM (cell movement of tumor cell lines); CN (central nervous system tumor); G (gliomatosis); MM (morbidity or mortality); MN (morphology of nervous system); N (necrosis); T (transport molecule). Proteins indicated as increased in treated were identified more often in the treated samples than in the untreated samples by MS/MS analysis of peaks identified to be significant by the LOOCV analysis. 


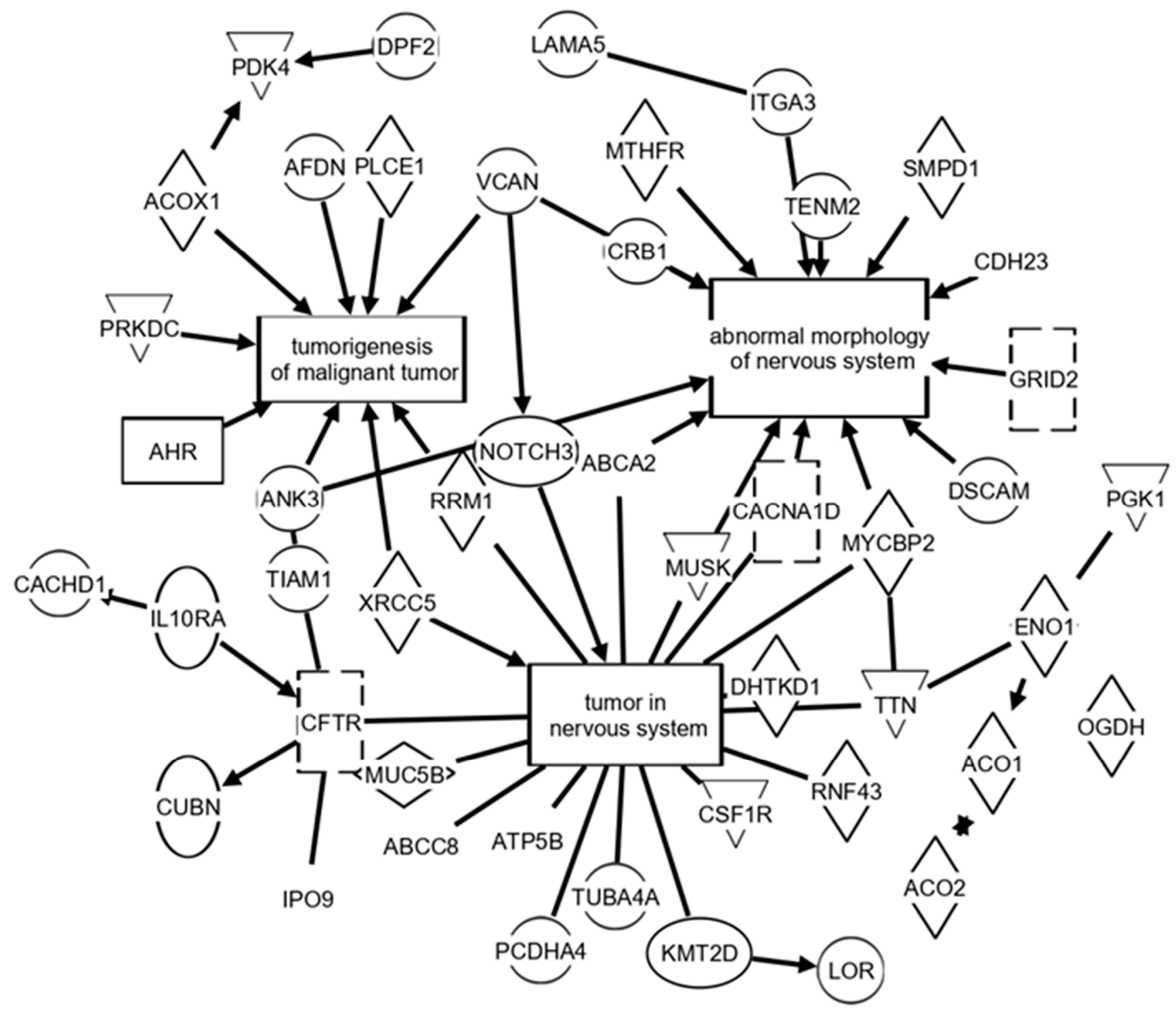

Figure 2. Tumorigenesis and nervous system pathways implicated by Ingenuity ${ }^{\circledR}$ Pathway Analysis $\left(\mathrm{IPA}^{\circledR}\right)$ of serum MS/MS results from untreated vs. treated rat brain tumor model. Values below each protein abbreviation represent the base-2 logarithm [untreated (\# hits)/treated (\# hits)] utilized by IPA software. Following this format, negative numbers indicate an increase in the number of hits observed in the drug-treated tumor samples compared to untreated tumor samples.

\section{Discussion}

OKN-007, formerly known as NXY-059, was found to have no adverse effects in human safety/toxicity studies [21,22], and we have not seen any adverse effects in any of our preclinical studies. We also have previously shown that OKN-007 is able to cross the blood-brain barrier (BBB) [4], and in fact, temporarily opens up the BBB for a brief $1-2 \mathrm{~h}$ period (based on its pharmacokinetics) [23]; however, the mechanism-of-action is currently unknown. It should also be noted that several of the preclinical models for HGGs have "leaky" blood-tumor barriers.

From our previous microarray data assessing genes that were down-regulated by OKN-007 in F98 tumors, compared to untreated tumors, there were 57 genes all associated with the master regulator TGF- $\beta 1$ [6]. Most of the associated genes were related to the ECM [6]. There were also indications that the mTOR pathway was affected by OKN-007 [6]. Of importance to the proteins discussed below in this study were ITGA1 (integrin alpha1), 2 and 4 (not 3, however), and ADAMTS2 (not 18, however). ITGA1 is a pre-malignant 
biomarker, which usually fosters therapy resistance and metastatic potential in pancreatic cancer [24]. Notch 3 activation was found to increase the expression of ITGA1 in ovarian cancer cells [25]. ITGA2 is highly expressed in several GBM cell lines [26]. ITGA4 is a metastasis-associated gene [27]. ADAMTS-2 is in the ADAMTS family, and is a procollagen N-proteinase [28]. ADAMTS-2 was found to be overexpressed in gastric cancer fibroblast cells [28]. In addition to the effect of OKN-007 on the ECM as a single agent, our group also established that when OKN-007 is linked with TMZ, it is even more effective in significantly increasing animal survival and decreasing tumor volumes in a G55 high-grade glioma xenograft model [6]. In vitro data also indicated that a combination of OKN-007 with TMZ also resulted in decreasing the cell proliferation of TMZ-resistant human GBM cell lines [6].

From this study, proteins of interest identified by tandem MS-MS that were decreased in sera from tumor-bearing rats treated with OKN-007, compared to untreated, included ABCA2, ATP5B, CNTN2, ITGA3, KMT2D, MYCBP2, NOTCH3, and VCAN. ABCA2 is part of the adenosine triphosphate-binding cassette transporter superfamily and is thought to exert important roles in the transmembrane transport of endogenous lipids, including myelin [29]. The relative expression level of ABCA2 mRNA was found to be significantly higher in oligodendrogliomas compared to anaplastic astrocytomas or GBM [29]. ATP5B has been found to be highly expressed in GBM tumor cells [30]. CNTN2 was found to be highly expressed in oligodendrogliomas [31]. ITGA3 is a cell surface adhesion protein that cooperates with ECM proteins which function in cancer metastasis [32,33]. This finding is somewhat supported by our previous gene data (see above). It was recently shown that brain-specific knockout of the H3K4 methyltransferase MLL4 (a COMPASS (COMplex of Proteins Associated with SET1)-like enzyme, also known as KMT2D) in mice spontaneously induces medulloblastoma [34]. The MYC binding protein 2 (MYCBP2) was found to be a binding partner for the epidermal growth factor receptor (EGFR), which is frequently mutated in various cancers [35]. It is well known that Notch3 activation promotes invasive glioma formation [36]. Versican (VCAN) is a large chondroitin sulphate proteoglycan produced by many tumor cell types, which includes high-grade glioma [37]. The increased expression of particular versican isoforms in the ECM is known to be involved in tumor cell growth, adhesion and migration [37]. Transforming growth factor-beta2 (TGF-beta2) is an essential modulator of glioma invasion, in part via the remodeling of the ECM [37]. Although our previous gene data indicated that TGF- $\beta 1$ was the master regulator [6], perhaps TGF- $\beta 2$ also plays an integral role, which would have to be further studied in association with the MOA for OKN-007.

Conversely, proteins of interest in tumor-bearing rats elevated following OKN-007 treatment included ABCA6, ADAMTS18, VWA8, MACF1, and LAMA5. Glioma patients with elevated expression of ABCC8 mRNA were found to have a longer survival [38]. ADAMTS18 is a part of the ADAMTS (A Disintegrin and Metalloproteinase with Thrombospondin motifs) family proteins, which take part in vital roles in cancer progression and metastasis in various cancers [39]. ADAMTS18 was previously found to be downregulated in numerous carcinoma cell lines, which suggested that it could be a tumor suppressor [40]. von Willebrand factor A domain-containing 8 (VWA8) were found to be significantly downregulated in breast cancer brain metastases [41]. Of some concern, MACF1 (microtubule actin cross-linking factor 1) was found to be predominately elevated in grade III-IV astrocytomas and grade IV glioblastoma, however when treated with TMZ, MACF1 is reduced and diminishes GBM cell proliferative capacity [42]. Perhaps when we combine OKN-007 with TMZ [6], the overall effect would be a decrease in MACF1, which we will have to study further in future studies. LAMA5 (laminin alpha5 subunit) is usually associated with cancer invasion/metastasis [43], and we need to further assess the role of serum levels of detected LAMA5 in association with high-grade gliomas, which has not yet been investigated to our knowledge. Of note, in zebrafish xenografts for GBM (U251MG), it was shown that adhesion to LAMA5 was found to inhibit cell invasion [44]. Our in vitro cell migration studies that assessed OKN-007 and OKN-007 combined with TMZ, indicated that G55 GBM cell migration was significantly decreased [6]; however, we did not assess 
LAMA5 levels, which we would need to study in future studies. Another future study should involve assessing whether TMZ combined with OKN-007 could affect the levels of serum proteins further.

These findings, in general, support our previous gene analysis that indicates that OKN-007 may be effective against the ECM (see Figure 3). These findings also surmise that OKN-007 may be more effective against oligodendrogliomas and possibly other brain tumors such as medulloblastoma, as well as other types of cancers.

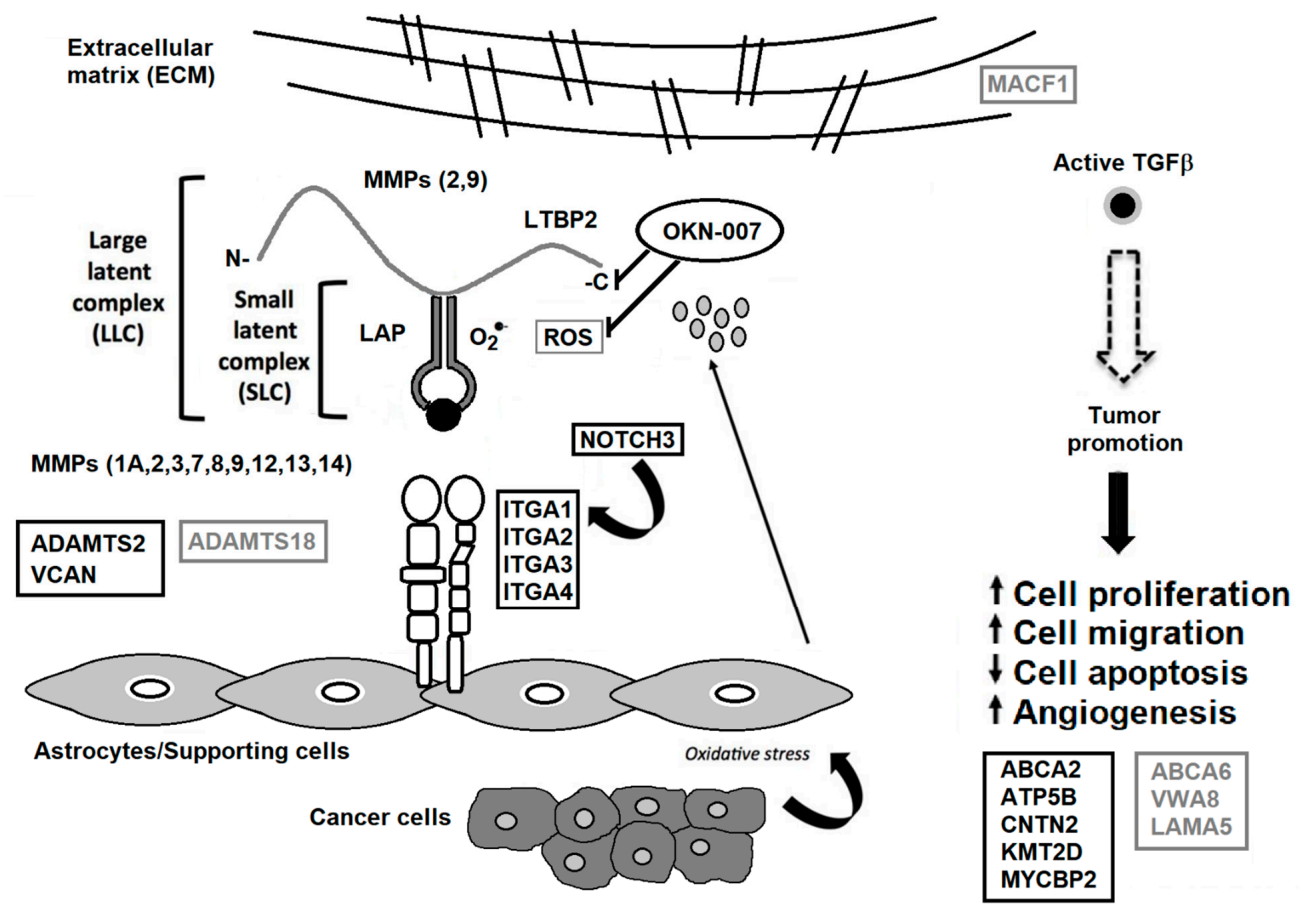

Figure 3. TGF- $\beta$ associated with the tumor microenvironment. Some matrix metalloproteinases (MMPs) cleave LTBP, which releases latent TGF- $\beta$ from the extracellular matrix (ECM). Various MMPs activate latent TGF- $\beta$ through proteolytic cleavage of the latency-associated peptide (LAP), whereas integrins expressed on astrocytes (ITGA1, 2, 3 and 4) bind to the large latent complex (LLC), and activate latent TGF- $\beta$ through MMP-dependent cleavage of LAP. Integrins (ITGA1, 2, 3 and 4) bind to the LLC and induce conformational changes in the latent complex through contractile action from activated astrocytes. Reactive oxygen species (ROS) produced by activated astrocytes from the induction of oxidative stress from nearby cancer cells may lead to the oxidation of the LAP domain and induce allosteric changes that release mature TGF- $\beta$ from LAP. The mature (active) form of TGF- $\beta$ can then bind to its receptor and then turn on tumor-promoting and tumor-suppressive properties. NOTCH3 activates ITGA1 [25], which are both decreased by OKN-007. VCAN is highly expressed in high-grade gliomas [37], which is decreased by OKN-007. ADAMTS2 is highly expressed in some cancers [28], which is decreased by OKN-007. ADAMTS18 is a tumor suppressor [40], which is elevated by OKN-007. During tumor promotion, activated TGF- $\beta$ led to decreased apoptosis and increased cell proliferation, cell migration, and angiogenesis [45]. OKN-007 is thought to act via LTBP and downregulates several genes associated with the ECM [6], and is also a free radical scavenger [4], resulting in the reversal of the major tumorigenic characteristics, i.e., increases tumor cell apoptosis and decreases cell proliferation, migration and vascular angiogenesis [46]. Other proteins decreased by OKN-007 include ABCA2, ATP5B, CNTN2, KMT2D, and MYCBP2. Other proteins elevated by OKN-007 include ABCA6, VWA8, LAMA5, and MACF1. Serum proteins decreased by OKN-007 are highlighted in black rectangular boxes. Serum proteins elevated by OKN-007 are depicted in gray rectangular boxes. Previous down-regulated genes include ITGA1, and 4, ADAMTS2, MMP 3, and 12, as well as several collagen genes (COL1A1, COL3A1, COL4A1, COL5A1, COL6A2, and COL7A1) [6]. Modified from Towner et al. [6] and Costanza et al. [45]. 


\section{Conclusions}

Several proteins were found to be altered in the blood sera of OKN-007-treated F98 tumor-bearing rats. Some of these proteins are highly associated with either gliomas or other cancers, and that OKN-007 can have an advantageous reversal effect in their expressions. There were a few proteins that seemed to be elevated with OKN-007-treatment, which may be of some concern but possibly could be alleviated when combined with other anti-cancer drugs (e.g., TMZ). Overall, the results indicate that when assessing the efficacy of OKN-007 in clinical trials, there may be protein biomarkers of interest that could be simply assessed in blood sera. Blood sera biomarkers used to evaluate therapeutic response against high-grade gliomas are currently non-existent, as far as we know.

Supplementary Materials: The following are available online at https://www.mdpi.com/article/10 .3390/brainsci12010100/s1, Table S1: Ratio of observations used in IPA.

Author Contributions: Conceptualization, R.A.T., J.H. (James Hocker) and J.H. (Jay Hanas); methodology, N.S., D.S., J.H. (James Hocker) and J.H. (Jay Hanas); validation, J.H. (James Hocker), J.H. (Jay Hanas) and N.S.; formal analysis, J.H. (James Hocker) and J.H. (Jay Hanas); investigation, R.A.T.; resources, R.A.T. and J.H. (Jay Hanas); data curation, J.H. (James Hocker) and J.B.; writing—original draft preparation, J.H. (James Hocker), J.H. (Jay Hanas) and R.A.T.; writing-review and editing, J.B., N.S. and D.S., visualization, R.A.T.; supervision, R.A.T. and J.H. (Jay Hanas); project administration, R.A.T.; funding acquisition, R.A.T. All authors have read and agreed to the published version of the manuscript.

Funding: This research was funded by the Oklahoma Center for the Advancement of Science (OCAST) and the Oklahoma Medical Research Foundation.

Institutional Review Board Statement: The study was conducted in accordance with the Oklahoma Medical Research Foundation Institutional Animal Care and Use Committee (protocol no. T0154\#1; approved 18 May 2010).

Informed Consent Statement: Not applicable.

Data Availability Statement: Data will be provided from the corresponding authors upon reasonable request.

Conflicts of Interest: R.A.T. has patents regarding the use of OKN-007 as a therapeutic agent for high-grade gliomas. All other authors declare no conflict of interest. The funders had no role in the design of the study, in the collection, analyses, or interpretation of data, in the writing of the manuscript, or in the decision to publish the results.

\section{References}

1. Lapointe, S.; Perry, A.; Butowski, N.A. Primary brain tumours in adults. Lancet 2018, 392, 432-446. [CrossRef]

2. Garteiser, P.; Doblas, S.; Watanabe, Y.; Saunders, D.; Hoyle, J.; Lerner, M.; He, T.; Floyd, R.A.; Towner, R.A. Multiparametric assessment of the anti-glioma properties of OKN007 by magnetic resonance imaging. J. Magn. Reson. Imaging 2010, 31, 796-806. [CrossRef] [PubMed]

3. Towner, R.A.; Gillespie, D.L.; Schwager, A.; Saunders, D.G.; Smith, N.; Njoku, C.E.; Krysiak, R.S., 3rd; Larabee, C.; Iqbal, H.; Floyd, R.A.; et al. Regression of glioma tumor growth in F98 and U87 rat glioma models by the Nitrone OKN-007. Neuro Oncol. 2013, 15, 330-340. [CrossRef]

4. Coutinho de Souza, P.; Smith, N.; Atolagbe, O.; Ziegler, J.; Njoku, C.; Lerner, M.; Ehrenshaft, M.; Mason, R.P.; Meek, B.; Plafker, S.M.; et al. OKN-007 decreases free radical levels in a preclinical F98 rat glioma model. Free Radic. Biol. Med. 2015, 87, 157-168. [CrossRef] [PubMed]

5. De Souza, P.C.; Smith, N.; Pody, R.; He, T.; Njoku, C.; Silasi-Mansat, R.; Lupu, F.; Meek, B.; Chen, H.; Dong, Y.; et al. OKN-007 decreases VEGFR-2 levels in a preclinical GL261 mouse glioma model. Am. J. Nucl. Med. Mol. Imaging 2015, 5, 363-378.

6. Towner, R.A.; Smith, N.; Saunders, D.; Brown, C.A.; Cai, X.; Ziegler, J.; Mallory, S.; Dozmorov, M.G.; Coutinho De Souza, P.; Wiley, G.; et al. OKN-007 Increases temozolomide (TMZ) Sensitivity and Suppresses TMZ-Resistant Glioblastoma (GBM) Tumor Growth. Transl. Oncol. 2019, 12, 320-335. [CrossRef] [PubMed]

7. Coutinho de Souza, P.; Mallory, S.; Smith, N.; Saunders, D.; Li, X.N.; McNall-Knapp, R.Y.; Fung, K.M.; Towner, R.A. Inhibition of Pediatric Glioblastoma Tumor Growth by the Anti-Cancer Agent OKN-007 in Orthotopic Mouse Xenografts. PLoS ONE 2015, 10, e0134276. 
8. Thomas, L.; Smith, N.; Saunders, D.; Zalles, M.; Gulej, R.; Lerner, M.; Fung, K.-M.; Carcaboso, A.M.; Towner, R.A. OKlahoma Nitrone-007: Novel treatment for diffuse intrinsic pontine glioma. J. Transl. Med. 2020, 18, 424. [CrossRef]

9. De Souza, P.C.; Balasubramanian, K.; Njoku, C.; Smith, N.; Gillespie, D.; Schwager, A.; Abdullah, O.; Ritchey, J.W.; Fung, K.-M.; Saunders, D.; et al. OKN-007 decreases tumor necrosis and tumor cell proliferation and increases apoptosis in a preclinical F98 rat glioma model. J. Magn. Reson. Imaging 2015, 42, 1582-1591. [CrossRef]

10. Barth, R.F.; Kaur, B. Rat brain tumor models in experimental neuro-oncology: The C6, 9L, T9, RG2, F98, BT4C, RT-2 and CNS-1 gliomas. J. Neuro-Oncol. 2009, 94, 299-312. [CrossRef] [PubMed]

11. Smith, N.; Saunders, D.; Jensen, R.L.; Towner, R.A. Association of decreased levels of lipopolysaccharide-binding protein with OKN-007-induced regression of tumor growth in an F98 rat glioma model. J. Neurosurg. 2020, 133, 1695-1703. [CrossRef]

12. Hocker, J.R.; Peyton, M.D.; Lerner, M.R.; Mitchell, S.L.; Lightfoot, S.A.; Lander, T.J.; Bates-Albers, L.M.; Vu, N.T.; Hanas, R.J.; Kupiec, T.C.; et al. Serum discrimination of early-stage lung cancer patients using electrospray-ionization mass spectrometry. Lung Cancer 2011, 74, 206-211. [CrossRef]

13. Hocker, J.R.; Mohammed, A.; Aston, C.E.; Brewer, M.; Lightfoot, S.A.; Rao, C.V.; Hanas, J.S. Mass profiling of serum to distinguish mice with pancreatic cancer induced by a transgenic kras mutation. Int. J. Cancer 2013, 133, 2662-2671. [PubMed]

14. Hocker, J.R.; Postier, R.G.; Li, M.; Lerner, M.R.; Lightfoot, S.A.; Peyton, M.D.; Deb, S.J.; Baker, C.M.; Williams, T.L.; Hanas, R.J.; et al. Discriminating patients with early-stage pancreatic cancer or chronic pancreatitis using serum electrospray mass profiling. Cancer Lett. 2015, 359, 314-324. [CrossRef]

15. Dittmar, G.A.G.; Wilkinson, C.R.M.; Jedrzejewski, P.T.; Finley, D. Role of a Ubiquitin-Like Modification in Polarized Morphogenesis. Science 2002, 295, 2442-2446. [CrossRef] [PubMed]

16. Altman, D.G.; Bland, J.M. Statistics Notes: Diagnostic tests 2: Predictive values. BMJ 1994, 309, 102. [CrossRef]

17. Altman, D.G.; Bland, J.M. Diagnostic tests. 1: Sensitivity and specificity. BMJ 1994, 308, 1552. [CrossRef]

18. Andreollo, N.A.; Santos, E.F.; Araújo, M.R.; Lopes, L.R. Rat's age versus human's age: What is the relationship? Arq. Bras. Cir. Dig. 2012, 25, 49-51. [CrossRef]

19. Rat Behavior and Biology. Rat Health Notes. How Old Is a Rat In Human Years? Last Updated 29 November 2012. Available online: http:/ / www.ratbehavior.org/RatYears (accessed on 8 September 2021).

20. Quinn, R. Comparing rat's to human's age: How old is my rat in people years? Nutrition 2005, 21, 775-777. [CrossRef]

21. Lyden, P.D.; Shuaib, A.; Lees, K.R.; Davalos, A.; Davis, S.M.; Diener, H.C.; Grotta, J.C.; Ashwood, T.J.; Hardemark, H.G.; Svensson, H.H.; et al. Safety and tolerability of NXY-059 for acute intracerebral hemorrhage: The CHANT Trial. Stroke 2007, 38, 2262-2269. [CrossRef] [PubMed]

22. Fong, J.J.; Rhoney, D.H. NXY-059: Review of Neuroprotective Potential for Acute Stroke. Ann. Pharmacother. 2006, 40, 461-471. [CrossRef]

23. Towner, R.A.; Saunders, D.; Lerner, M.; Silasi Mansat, R.; Yuan, T.; Barber, D.; Faakye, J.; Nyul-Toth, A.; Csiszar, A.; GreenwoodVan Meerveld, B.; et al. Temporary opening of the blood-brain barrier with the nitrone compound OKN-007. Am. J. Nucl. Med. Mol. Imaging 2021, 11, 363-373.

24. Gharibi, A.; La Kim, S.; Molnar, J.; Brambilla, D.; Adamian, Y.; Hoover, M.; Hong, J.; Laurelin, W.; Wolfenden, L.; Kelber, J.A. ITGA1 is a pre-malignant biomarker that promotes therapy resistance and metastatic potential in pancreatic cancer. Sci. Rep. 2017, 7, 10060. [CrossRef]

25. Price, J.C.; Azizi, E.; Naiche, L.A.; Parvani, J.G.; Shukla, P.; Kim, S.; Slack-Davis, J.K.; Pe'Er, D.; Kitajewski, J.K. Notch3 signaling promotes tumor cell adhesion and progression in a murine epithelial ovarian cancer model. PLoS ONE 2020, 15, e0233962. [CrossRef] [PubMed]

26. Guo, P.; Moses-Gardner, A.; Huang, J.; Smith, E.R.; Moses, M.A. ITGA2 as a potential nanotherapeutic target for glioblastoma. Sci. Rep. 2019, 9, 6195. [CrossRef]

27. Kovářová, D.; Plachý, J.; Kosla, J.; Trejbalová, K.; Čermák, V.; Hejnar, J. Downregulation of HOPX Controls Metastatic Behavior in Sarcoma Cells and Identifies Genes Associated with Metastasis. Mol. Cancer Res. 2013, 11, 1235-1247. [CrossRef]

28. Jiang, C.; Zhou, Y.; Huang, Y.; Wang, Y.; Wang, W.; Kuai, X. Overexpression of ADAMTS-2 in tumor cells and stroma is predictive of poor clinical prognosis in gastric cancer. Hum. Pathol. 2019, 84, 44-51. [CrossRef] [PubMed]

29. Soichi, O.; Masanori, N.; Hideo, T.; Kazunori, A.; Nobuya, I.; Jun-ichi, K. Clinical significance of ABCA2' a possible molecular marker for oligodendrogliomas. Neurosurgery 2007, 60, 707-714, discussion 714. [PubMed]

30. Xu, G.; Li, J.Y. ATP5A1 and ATP5B are highly expressed in glioblastoma tumor cells and endothelial cells of microvascular proliferation. J. Neuro-Oncol. 2016, 126, 405-413. [CrossRef] [PubMed]

31. Yu, F.; Fu, W.-M. Identification of differential splicing genes in gliomas using exon expression profiling. Mol. Med. Rep. 2015, 11, 843-850. [CrossRef]

32. Jiao, Y.; Li, Y.; Liu, S.; Chen, Q.; Liu, Y. ITGA3 serves as a diagnostic and prognostic biomarker for pancreatic cancer. OncoTargets Ther. 2019, 12, 4141-4152. [CrossRef] [PubMed]

33. Kawataki, T.; Yamane, T.; Naganuma, H.; Rousselle, P.; Andurén, I.; Tryggvason, K.; Patarroyo, M. Laminin isoforms and their integrin receptors in glioma cell migration and invasiveness: Evidence for a role of alpha5-laminin(s) and alpha3beta1 integrin. Exp. Cell Res. 2007, 313, 3819-3831. [CrossRef] [PubMed]

34. Dhar, S.S.; Zhao, D.; Lin, T.; Gu, B.; Pal, K.; Wu, S.; Alam, H.; Lv, J.; Yun, K.; Gopalakrishnan, V.; et al. MLL4 Is Required to Maintain Broad H3K4me3 Peaks and Super-Enhancers at Tumor Suppressor Genes. Mol. Cell 2018, 70, 825-841.e6. [CrossRef] 
35. Erdem-Eraslan, L.; Gao, Y.; Kloosterhof, N.K.; Atlasi, Y.; Demmers, J.; Sacchetti, A.; Kros, J.M.; Sillevis Smitt, P.; Aerts, J.; French, P.J. Mutation specific functions of EGFR result in a mutation-specific downstream pathway activation. Eur. J. Cancer 2015, 51, 893-903. [CrossRef] [PubMed]

36. Pierfelice, T.J.; Schreck, K.; Dang, L.; Asnaghi, L.; Gaiano, N.; Eberhart, C.G. Notch3 Activation Promotes Invasive Glioma Formation in a Tissue Site-Specific Manner. Cancer Res. 2011, 71, 1115-1125. [CrossRef]

37. Arslan, F.; Bosserhoff, A.K.; Nickl-Jockschat, T.; Doerfelt, A.; Bogdahn, U.; Hau, P. The role of versican isoforms V0/V1 in glioma migration mediated by transforming growth factor-beta2. Br. J. Cancer 2007, 96, 1560-1568. [CrossRef]

38. Zhou, K.; Liu, Y.; Zhao, Z.; Wang, Y.; Huang, L.; Chai, R.; Li, G.; Jiang, T. ABCC8 mRNA expression is an independent prognostic factor for glioma and can predict chemosensitivity. Sci. Rep. 2020, 10, 12682. [CrossRef]

39. Zhang, L.; Liu, Y.; Zheng, P. Downregulation of ADAMTS18 May Serve as a Poor Prognostic Biomarker for Cervical Cancer Patients. Appl. Immunohistochem. Mol. Morphol. 2018, 26, 670-675. [CrossRef]

40. Jin, H.; Wang, X.; Ying, J.; Wong, A.H.Y.; Li, H.; Lee, K.Y.; Srivastava, G.; Chan, A.T.C.; Yeo, W.; Ma, B.; et al. Epigenetic identification of ADAMTS18 as a novel 16q23.1 tumor suppressor frequently silenced in esophageal, nasopharyngeal and multiple other carcinomas. Oncogene 2007, 26, 7490-7498. [CrossRef] [PubMed]

41. Yuan, F.; Wang, W.; Cheng, H. Co-expression network analysis of gene expression profiles of HER2+ breast cancer-associated brain metastasis. Oncol. Lett. 2018, 16, 7008-7019. [CrossRef]

42. Afghani, N.; Mehta, T.; Wang, J.; Tang, N.; Skalli, O.; Quick, Q.A. Microtubule actin cross-linking factor 1, a novel target in glioblastoma. Int. J. Oncol. 2017, 50, 310-316. [CrossRef] [PubMed]

43. Galatenko, V.V.; Maltseva, D.V.; Galatenko, A.V.; Rodin, S.; Tonevitsky, A.G. Cumulative prognostic power of laminin genes in colorectal cancer. BMC Med. Genom. 2018, 11, 9. [CrossRef]

44. Gamble, J.T.; Reed-Harris, Y.; Barton, C.L.; La Du, J.; Tanguay, R.; Greenwood, J.A. Quantification of glioblastoma progression in zebrafish xenografts: Adhesion to laminin alpha 5 promotes glioblastoma microtumor formation and inhibits cell invasion. Biochem. Biophys. Res. Commun. 2018, 506, 833-839. [CrossRef] [PubMed]

45. Costanza, B.; Umelo, I.A.; Bellier, J.; Castronovo, V.; Turtoi, A. Stromal Modulators of TGF- $\beta$ in Cancer. J. Clin. Med. 2017, 6, 7. [CrossRef] [PubMed]

46. Zalles, M.; Smith, N.; Saunders, D.; Lerner, M.; Fung, K.; Battiste, J.; Towner, R.A. A tale of two multi-focal therapies for glioblastoma: An antibody targeting ELTD1 and nitrone-based OKN-007. J. Cell. Mol. Med. 2021, 26, 520-582. [CrossRef] 